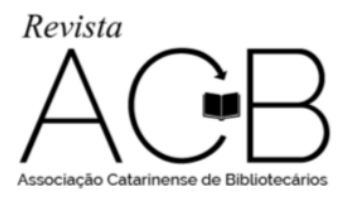

\title{
ACESSIBILIDADE E SERVIÇOS INCLUSIVOS PARA MINORIAS SOCIAIS: A BIBLIOTECA DO INSTITUTO NACIONAL DE EDUCAÇÃO DE SURDOS
}

\author{
Sarah Miglioli ${ }^{1}$ \\ smiglioli@gmail.com \\ Gilmara Almeida dos Santos ${ }^{2}$ \\ gilmaradossantos@gmail.com
}

Resumo: Este artigo aborda o papel da biblioteca como propulsora do acesso e promoção da informação para minorias sociais. Expõe a importância da atuação da biblioteca na diversidade, cidadania e inclusão social. Trata-se de relato de experiência em acessibilidade para surdos na biblioteca do Instituto Nacional de Educação de Surdos. Apresenta parâmetros de acessibilidade para surdos e propõe medidas para a integração do indivíduo surdo na biblioteca.

Palavras-chave: Acessibilidade. Pessoa com deficiência. Deficiência auditiva. Surdos. Minorias sociais.

\section{INTRODUÇÃO}

Dados do Instituto Brasileiro de Geografia e Estatística (2010) revelam mais de 45 milhões de pessoas com necessidades especiais, que variam de acordo com critérios de deficiências auditiva, visual, motora e/ou mental. Cerca de um quinto deste número apresenta algum grau de deficiência auditiva (IBGE, 2010). Embora os deficientes possam ser agrupados sob um rótulo único ou por características semelhantes, é importante notar que indivíduos com deficiência visual/motora são mantidos longe de "coisas" - uma alusão a objetos e ao próprio espaço físico; enquanto os deficientes auditivos estão mantidos separados de pessoas - se referindo à dificuldade de comunicação. $\mathrm{O}$ axioma pretende informar que a deficiência visual aplaca grande influência sobre a locomoção, mas a comunicabilidade do indivíduo é mantida. No caso dos deficientes auditivos, a dificuldade de aquisição da linguagem oral agrava a capacidade comunicativa, e consequentemente, a interação interpessoal.

A surdez pode ser denominada também da deficiência invisível, visto que, de maneira geral, não se percebe que um indivíduo é deficiente auditivo, a menos que este utilize algum aparelho auditivo ou faça uso da língua de sinais para se comunicar. Essa característica também exerce grande impacto na atuação e integração dos deficientes auditivos/surdos em sociedade. Deficientes auditivos são muitas vezes retratados como um grupo homogêneo, entretanto, nove subpopulações distintas podem ser identificadas, segundo Hagemeyer (1992, p. 8). Cada grupo agrega um conjunto diferente de técnicas de comunicação e de necessidades de informação: (1) pessoas que se comunicam fluentemente em Libras como língua principal; (2) pessoas bilíngues que se comunicam fluentemente em Libras e Português; (3) pessoas com deficiência auditiva que se comunicam principalmente por meio da fala/oralização; (4) adultos que se tornaram surdos depois de ter tido a experiência de ouvir e após ter adquirido a fala, e portanto, se comunicam através do Português; (5) idosos que têm deficiência auditiva como resultado do

\footnotetext{
${ }^{1}$ Doutoranda em Ciência da Informação pelo Instituto Brasileiro de Informação em Ciência e Tecnologia (IBICT), convênio com a Universidade Federal do Rio de Janeiro (UFRJ). Mestre em Ciência da Informação pelo Instituto Brasileiro de Informação em Ciência e Tecnologia (IBICT), convênio com a Universidade Federal do Rio de Janeiro (UFRJ). Graduada em Biblioteconomia pela Universidade Federal do Estado do Rio de Janeiro (UNIRIO). Bibliotecária do Instituto Nacional de Educação de Surdos (INES/MEC).

2 Mestre em Memória Social pela Universidade Federal do Rio de Janeiro (UNIRIO). Especialista em Biblioteconomia. Graduada em Letras, habilitação em Português e Literatura em Língua Portuguesa pela Universidade do Estado do Rio de Janeiro (UERJ).
} 
processo de envelhecimento e e comunicam pelo Português; (6) pessoas utilizadoras de língua gestuais que não usam nem Libras nem Português; (7) Pessoas com dificuldade de audição que têm resíduo auditivo, porém pouco eficaz; (8) pessoas surdas que também são cegas, os denominados surdo cegos; (9) pessoas surdas de qualquer uma das categorias acima que possuem familiares ouvintes (pais, filhos, esposas, etc.).

A auto percepção dos indivíduos deficientes desempenha papel primordial na determinação de qual grupo pertence, e consequentemente, as especificidades das suas necessidades de informação. Decerto, tais fatores influenciam o modo como os serviços de biblioteca são oferecidos a usuários surdos, mas apesar disso, bibliotecários e demais profissionais que concebem tais serviços podem não conhecer profundamente os elementos essenciais que particularizam este usuário.

$\mathrm{Na}$ perspectiva da acessibilidade em bibliotecas, ainda, pensa-se primeiramente em mudanças no espaço físico, melhorias na sinalização, adaptação de recursos maquínicos, a exemplo das categorias da avaliação das bibliotecas de curso superior pelo Ministério da Educação, o SINAES - Sistema Nacional de Avaliação da Educação Superior (BRASIL, 2003). Isto é, quando comparamos recursos despendidos, torna-se eloquente a tendência em priorizar serviços para deficientes visuais e/ou físicos, mas pouco ou nenhum para os deficientes auditivos. Para o público em questão, o requisito está na necessidade de acessibilidade comunicacional e informacional, através do acesso a uma forma de comunicação - seja a Libras, tecnologia, etc. - e posteriormente o acesso à informação em si.

Essa diferenciação em critérios de acessibilidade abordada por Sassaki (1997, p. 27), para quem seis são os eixos que compõem o conceito da acessibilidade: arquitetônico, comunicacional, metodológico, instrumental, programático, e atitudinal. Para Sassaki (1997, p. 38), a plena acessibilidade leva à inclusão que seria "como um paradigma de sociedade, o processo pelo qual os sistemas sociais comuns são tornados adequados para toda a diversidade humana [...] com a participação das próprias pessoas na formulação e execução dessas adequações". Assim sendo, as necessidades de informação dos usuários surdos seja a necessidade de informação para conhecimento, seja a necessidade de informação para a ação (LE COADIC, 2004, p. 40), só podem ser atendidos por meio de um enfoque na acessibilidade comunicacional e atitudinal volta para este público.

$\mathrm{O}$ acesso à informação é vital para um indivíduo participar plenamente na sociedade, e o oposto também é verdadeiro - a falta de informação contribui para a exclusão social. Poucos estudos foram realizados enfatizando a responsabilidade das bibliotecas no atendimento aos surdos. No ano 2000, a International Federation of Library Associations and Institutions (IFLA) produziu o documento "Diretrizes para serviços de biblioteca para surdos", e, ainda assim, citaram trabalhos publicados de décadas anteriores. E embora a Lei de Libras 10.436 tenha sido efetivada 2002 (BRASIL, 2002), juntamente do Decreto 5.626 de 2005 (BRASIL, 2005), indicando a Libras como segunda língua oficial do Brasil, pouco muita dúvida envolve o tema no que tange os serviços de biblioteca.

Estas circunstâncias impõem um desafio na abordagem sobre como a biblioteca pode atender às necessidades destes usuários. No atual panorama de promoção de igualdades sociais e respeito às minorias, as necessidades dos surdos tornam ainda mais urgentes a aproximação com as bibliotecas, que por sua vez encara um cenário oportuno para atualização.

O Instituto Nacional de Educação de Surdos - INES, órgão ligado diretamente ao Ministério da Educação, foi uma das primeiras instituições no Brasil a oferecer curso de graduação voltado para temática da surdez e o público surdo, além de educação básica exclusiva para crianças surdas. O Instituto conta com mais de 60 vagas para graduação e pós graduação por semestre e mais de 600 alunos na educação básica (BRASIL, 2015). Como resultado, o número proporcional de alunos surdos no curso superior é maior do que em universidades públicas tradicionais, que passaram a receber nos últimos anos alunos deficientes cotistas.

A biblioteca do INES oferece suporte a todos os alunos, professores e funcionários do instituto. Após imersão na comunidade e conhecimento da identidade dos surdos e eticidade da comunidade, aliados à aprendizagem da língua de sinais pelos membros da biblioteca, foi possível alcançar um atendimento de excelência através da plena comunicação. A eficácia do atendimento foi estabelecida após 


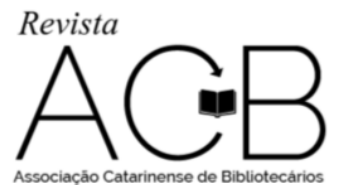

Acessibilidade e serviços inclusivos para minorias sociais: a biblioteca do Instituto Nacional de Educação de Surdos - Sarah Miglioli e Gilmara Almeida dos Santos

o reconhecimento da biblioteca como espaço identitário e de liberdade pelo público surdo. As necessidades de informação foram analisadas e processadas dentro do domínio da língua de sinais para que as informações refletissem nos serviços oferecidos.

Em um esforço para reconhecer esses indivíduos como membros de uma minoria social distinta, este artigo emprega o termo surdo para se referir a indivíduos com perda auditiva, acolhendo o conceito do Decreto 5.626 de 2005, que considera a "pessoa surda aquela que, por ter perda auditiva, compreende e interage com o mundo por meio de experiências visuais, manifestando sua cultura principalmente pelo uso da Língua Brasileira de Sinais - Libras". Ademais, há o consenso na área da pesquisa em surdez de que termo "deficiente auditivo" é usado para designar pessoas com surdez pós-linguística - quando a perda da audição ocorre depois da aquisição da língua oral; e o termo "surdo" para pessoas com surdez pré-linguística - quando a perda da audição ocorre antes da fase de aquisição da língua oral, sendo, portanto, em sua maioria indivíduos que fazem uso da língua de sinais. Levando-se em consideração que o público do INES e da Biblioteca é formado majoritariamente por surdos, como a terminologia da nomenclatura da instituição a que este artigo se dedica utiliza o termo "surdo" - em Instituto Nacional de Educação de Surdos (grifo nosso) - e não deficiente auditivo, é também premissa para o uso do primeiro termo.

Assim, o objetivo primário do estudo é abordar o acesso à informação para minorias sociais dentro do papel das bibliotecas. Ademais, relata experiência dos serviços acessíveis para atender as necessidades dos alunos surdos na Biblioteca do Instituto Nacional de Educação de Surdos, oferecendo orientações e parâmetros de acessibilidade informacional para usuários surdos em bibliotecas não especializadas.

\section{PANORAMA DA SURDEZ}

Indivíduos surdos ou com deficiência auditiva costumam definir-se de forma diferente de outras deficiências físicas dependendo do contexto social. Membros da comunidade surda têm compreendido a surdez como uma designação cultural e/ou sociolinguística, e não uma identificação definida por sua incapacidade de ouvir determinado nível de decibéis ou pela própria perspectiva da deficiência (STROBEL, 2008). Há também os indivíduos com perda parcial e que fazem leitura labial e se consideram "ouvintes".

Amplo corpo de pesquisa sobre a cultura surda foi considerada na elaboração deste estudo (SKLIAR, 2005; QUADROS, 2008; STROBEL, 2008; KARNOPP, 2011). A análise cultural sobre surdos leva a entender o panorama da literatura que abrange temáticas da comunidade de surdos atualmente, colocando-os como um grupo sociolinguístico distinto e fornecendo uma visão geral do recente movimento de inclusão de surdos no ensino superior, do qual o INES é uma parte atuante.

Um tema comum da literatura em Educação de Surdos é a experiência destes alunos em sala de aula. Vários estudos fornecem uma visão sobre os desafios que os surdos enfrentam no ensino superior (MANENTEL, RODRIGUES, 2007; CRUZ, DIAS, 2009; BISOL, 2010), muito em virtude da dificuldade com a aquisição/domínio da Língua Portuguesa (CAPOVILLA, 2008) e apontam para níveis baixos de leitura encontradas entre surdos e especificidades na aprendizagem da língua escrita.

Diversos fatores contribuem para esses percalços, incluindo: dificuldade de compreensão da língua falada e/ou escrita em sala de aula; dificuldade de compreensão em sala de aula como um todo, dificuldade em navegar ferramentas de busca na Internet e deficiências em habilidades de leitura crítica, como a detecção do viés do autor e compreensão de pontos-de-vista (MANENTEL; RODRIGUES; PALAMIN, 2010). Os dois últimos pontos são pertinentes para a realização de pesquisa acadêmica, que depende da competência no uso de ferramentas de busca não somente para localizar informação, mas também para avaliar criticamente a relevância e a validade desses recursos.

Verifica-se uma escassez de pesquisa sobre as necessidades dos usuários com deficiência, menos ainda aqueles que são surdos e com dificuldades de audição. Entre os estudos publicados, prevalente está a necessidade de treinamento extensivo da equipe da biblioteca para prestar um melhor serviço para os usuários com necessidades especiais (IFLA, 2010). Outras fontes observam que essa formação exige que 


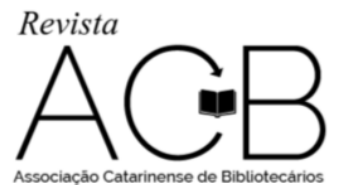

Acessibilidade e serviços inclusivos para minorias sociais: a biblioteca do Instituto Nacional de Educação de Surdos - Sarah Miglioli e Gilmara Almeida dos Santos

a equipe seja instruída em códigos de conduta específicos para usuários dependendo da natureza da sua deficiência (MAZZONI, 2001). Além de alterar o comportamento da equipe, a literatura cita a possibilidade de transformar o ambiente da biblioteca, a fim de eliminar possíveis obstáculos à utilização física dos usuários (FONSECA, GOMES, VANZ, 2012; SANTOS, DINIZ, SÁ, 2014; ANDRADE, LUCAS, NASCIMENTO, 2015). Embora as sugestões de mudanças arquitetônicas sejam principalmente indicadas para usuários com deficiência visual ou usuários com limitações de mobilidade, é importante notar que as alterações no ambiente físico da biblioteca podem melhorar a acessibilidade também para surdos e deficientes auditivos. Por exemplo, uma sinalização clara e visível pode ajudar o surdo a navegar no espaço da biblioteca sozinho, sem a necessidade de dependência de instrução (ISHIMOTO, RAMÃO, 2015), dando-lhe autonomia e permitindo assim o uso democrático e igualitário do espaço.

Em termos gerais, essas necessidades incluem uma abordagem menos oral à comunicação com os usuários surdos, a compreensão de que os usuários surdos podem não ter tido boas ou qualquer experiência com bibliotecas no passado, e o interesse em interagir com eficácia com este indivíduo passa a ser orgânico para a inserção da comunidade dos deficientes auditivos.

Outras pesquisas oferecem recomendações para servir os usuários com deficiência auditiva (SOUSA, 2010; MIRANDA e MIRANDA, 2015) ou apontam brevemente para os usuários surdos dentro do panorama mais amplo de prestação de serviço de biblioteca para pessoas com deficiência (CONEGLIAN, CASARIN, 2006). De todo modo, as pesquisas anteriores possuem enfoque divergente da experiências de usuários surdos que este estudo busca, que é tratar do acesso à informação para minorias sociais inseridos do papel social da biblioteca, focando as reais necessidades de informação dos usuários surdos.

\section{PAPEL DAS BIBLIOTECAS EM RELAÇÃO A MINORIAS SOCIAIS E USUÁRIOS COM NECESSIDADES ESPECIAIS}

O surgimento de demandas por igualdade de acesso a recursos associados a uma demanda de reconhecimento de identidades únicas e muitas vezes em processos de transformação tem demandado uma mudança de perspectiva das instituições. Cada vez mais minorias sociais têm reclamado seus direitos e tem passado a ser considerados para além dos limites de seus círculos sociais tradicionais.

A biblioteca tem tradicionalmente estado na vanguarda dos programas em favor da alfabetização e das necessidades de informação de grupos socialmente marginalizados (idosos, desempregados, refugiados, população carcerária, população de rua, etc.), devido ao caráter social inerente a sua natureza. Há exemplos de bibliotecas que fornecem serviços para atender às necessidades de grupos especiais, contudo, é de compreensão comum que estes serviços especializados ou direcionados podem ser caros ou difíceis de serem mantidos.

A questão dos grupos minoritários é que aqueles que servem a esses usuários tentam, através de procedimentos e práticas, homogeneizar o serviço, e do ponto de vista da prestação de serviço e do tratamento com o público, todos os usuários indistintamente devem ser definidos como especiais. Nesse sentido, a identificação do momento de interseção entre sistema e usuário deve ser visto como uma busca pelo pleno atendimento às especificidades.

A diversidade é declaradamente um valor fundamental para bibliotecas, embora seu enfoque continue a ser majoritariamente homogêneo. O caráter social é um valor central em termos do papel da biblioteca e sua a contribuição para melhorar ou resolver os problemas críticos da sociedade. A persistência e crescimento de desigualdades, combinada com políticas que não conseguem proteger os direitos e as oportunidades de minorias sociais, torna essencial priorizar a diversidade e justiça social nas bibliotecas.

Um importante aspecto centra-se na mudança social em bibliotecas a partir da perspectiva da composição dos membros da biblioteca em relação a usuários reais e potenciais. Neste contexto, aumentar a diversidade dos recursos humanos dentro de bibliotecas é um pré-requisito para efetivamente alavancar 
bibliotecas na causa da cidadania. Além de treinada, uma equipe com membros com diversidade em bibliotecas é importante não apenas como uma medida de quão bem a biblioteca reflete a sociedade, mas também porque uma equipe diversificada e inclusiva permite fornecer uma gama mais ampla de perspectivas, talentos, conhecimentos e experiências.

Sendo assim, bibliotecas podem exercer uma influência sobre a diversidade, ou sobre a falta dela, através de escolhas que fazem no cumprimento das missões primárias de recolher, preservar e fornecer acesso à informação. Demonstrar o potencial que os padrões e práticas têm sobre a forma como o conhecimento é descrito e organizado, e, portanto, como e quem pode descobrir, encontrar e usar os recursos em coleções de bibliotecas, torna-se atividade primordial.

As decisões tomadas sobre recolher e preservar e a aquisição devem estar voltadas para a democracia e equidade. O desenvolvimento de coleções deve resultar em coleções que reflitam a diversidade das comunidades a qual servem, através da busca por recursos de e sobre minorias sociais, mesmo que não seja parte do padrão de seleção, a fim de evitar escolhas tendenciosas ou preconceituosas.

Atividades na biblioteca podem proporcionar uma voz mais ativa na comunidade, como recomendações sobre as escolhas de materiais de leitura, e também compartilhamento de informações mais amplas sobre os recursos. Para aumentar o acesso e conhecimento sobre seus recursos e serviços, a biblioteca também deve participar de eventos de minorias sociais e grupos marginalizados, mostrando sua disponibilidade em potencial e criando vínculos identitários com os membros destes subgrupos. Para bibliotecas atenderem verdadeiramente as demandas de minorias sociais e proporcionar a missão de ajudar a alcançar justiça social para seus membros, não só deverá prestar atenção às necessidades dinâmicas da comunidade, mas também precisa criar parcerias não tradicionais com bases formais e informais dentro das comunidades minoritárias.

Historicamente, as bibliotecas têm sido consideradas o coração de suas instituições, e assim deverão permanecer, se e quando passar a serem vistos como modelos de diversidade, equidade e cidadania. Embora a biblioteca não tenha sido pensada primeiramente como um espaço promotor da inclusão com serviços de informação que permeiam a noção de assistência social, ela pode cumprir perfeitamente esse papel. $\mathrm{O}$ aspecto democratizador e libertário das bibliotecas, que se abstêm da visão de lucro impregnada na sociedade, tornam-nas o espaço adequado para promoção da cidadania através da absorção de membros de minorias sociais em mais amplo espectro.

Grupos marginalizados como imigrantes, deficientes, LGBT, população de rua, etc., são minorias vulneráveis que podem encontrar na biblioteca um espaço libertário para atender às suas necessidades mais desassistidas. No Brasil, o espaço da biblioteca não é visto como função para atendimento em serviço social, mas no âmbito da biblioteca poderão esses usuários encontrar acolhimento para buscar o atendimento a necessidades mais essenciais, como busca por vagas de emprego, informações sobre seus direitos, acesso a informações sobre serviços, etc.

Nestas circunstâncias, parece essencial investir pesquisas com maior amplitude social, despendendo esforço sobre os problemas de informação de grupos negligenciados. As bibliotecas têm um papel crucial a desempenhar tanto na resolução de problemas práticos como na formulação de teorias, inclusive referentes à especificidade da inclusão de minorias sociais, como no caso dos surdos.

$\mathrm{Na}$ tentativa de proporcionar igualdade de acesso à informação devemos levar em conta as necessidades especiais do usuário surdo. Não se pode generalizar inadvertidamente que os surdos foram um grupo típico de adultos que podem se expressar, mas que possuem nível de leitura abaixo da média, quando na realidade a comunidade é composta de indivíduos com níveis muito distintos de realização intelectual, necessidades de informação e preferências de comunicação. 


\section{A EXPERIÊNCIA DOS USUÁRIOS SURDOS NA BIBLIOTECA DO INSTITUTO NACIONAL DE EDUCAÇÃO DE SURDOS}

Neste contexto, até o momento da realização deste estudo, havia poucas fontes de informação registradas sobre o setor da biblioteca do INES. A maior parte das informações usadas neste artigo é de origem apócrifa ou canais informais. Em função disso, o artigo se caracteriza como relato da experiência.

O Instituto Nacional de Educação de Surdos foi criado em meados do século XIX por iniciativa do surdo francês E. Huet, tendo como primeira denominação Collégio Nacional para Surdos-Mudos. Em 1855, E. Huet mostra ao Imperador D. Pedro II um relatório que expunha a intenção de fundar uma escola para surdos no Brasil, inspirado também na sua atuação como diretor de uma instituição para surdos na França (MONTEIRO, 2006; STROBEL, 2009).

O instituto teve o início de sua atuação a partir de 1856, e ao longo da história sofreu diversas mudanças de nomenclatura, entre as quais a principal foi a exclusão do termo "mudo" (especialmente porque a surdez não possui relação com a mudez, que se constitui, na verdade, em outra deficiência) e a inclusão da palavra "educação", em 1957 (BRASIL, 2015). Por ter sido durante décadas a única instituição voltada para surdos, tanto para o Brasil quanto para alguns países próximos, a instituição se firmou como referência para surdos e na temática da surdez.

A Biblioteca, além de servir as necessidades dos alunos surdos, atende outros usuários incluindo pais e professores de surdos; profissionais trabalhando com os deficientes auditivos, por exemplo, fonoaudiólogos, terapeutas da fala e médicos; e usuários ouvintes, que desejam obter informações gerais sobre surdez e pesquisadores de universidades de todo o mundo interessados no tema para sua pesquisa (BRASIL, 2015).

O desafio de organizar a biblioteca, com base em materiais coletados por anos, mas que jaziam sem uma organização informacional formal, foi processo contundente. Pensar no espaço que atendesse às necessidades da comunidade interna do Instituto, formada em sua maioria por pessoas com essas características, bem como ao amplo público externo mencionado acima, despertou o aprofundamento sobre as particularidades desse público.

$\mathrm{O}$ treinamento de atendimento ao usuário incluiu componentes que ajudam a equipe a entender mais sobre as demandas de serviço, incluindo como atender positivamente as expectativas dos usuários e lidar eficazmente com os surdos em até mesmo interações mais difíceis, como com usuários com múltiplas deficiências. A equipe de bibliotecárias possui conhecimento acerca das especificidades das tipologias e da eticidade da comunidade surda e foi capacitada no curso de Libras, oferecido pelo próprio Instituto e ministrado por professores surdos, além de possuir um profissional surdo agindo no serviço de referência.

Ser uma equipe capacitada na língua de sinais e ativa na comunidade permitiu entre outras questões, tornar a biblioteca identificável pessoalmente, e a incentivar os surdos a manter contato. O fato de conhecer os profissionais e saber que tinham o domínio da língua de sinais proporciona o estabelecimento de um vínculo importante para a inclusão destes usuários.

O espaço da sala de leitura, normalmente sacralizado de silêncio nas bibliotecas, pôde também servir como espaço de pouco estímulo visual para os surdos. Tal conceito não havia antes na instituição, e permitiu a promoção da concentração e incentivo à leitura. A identidade visual foi pensada na autonomia e fácil identificação por usuários surdos. Grandes particularidades puderam ser somadas a políticas de promoção à acessibilidade, como a sinalização visual com língua de sinais e apresentando, além da classificação decimal para organização do conhecimento do acervo, mas também os termos representativos, com os quais estavam habituados.

Toda a equipe é treinada para auxiliar, em Libras, os alunos surdos a localizar, recuperar e acessar as informações da coleção de materiais impressos e vídeo, bem como demais materiais. No início de cada semestre, a equipe da biblioteca estabelece comunicação com professores, estudantes e usuários para analisar sua aprendizagem e necessidades de informações, auxiliando na preparação contínua de materiais 
e recursos relevantes que atendam a essas necessidades. Além de adquirir materiais sobre este assunto, a biblioteca também fornece bibliografias e providencia a realização de levantamentos para exposições, palestras e seminários sobre os surdos e sobre a surdez.

A biblioteca atende hoje um número proporcionalmente muito maior de alunos se comparado ao início de sua implementação formal, há seis anos (RELATÓRIO...,2015). O principal fator foi a mudança de perspectiva dos usuários surdos em relação à biblioteca, primeiro pela descoberta de que o termo biblioteca abarcava muito mais que uma "coleção de livros", e estava vinculada a um sistema de organização mais complexo visando ser um facilitador ao acesso.

O serviço de referência atingiu novo padrão no serviço acessível quando passou a contar com um profissional surdo no atendimento de referência, apresentando um novo olhar para os usuários surdos em relação ao que a biblioteca enquanto sistema de informação e espaço democrática se caracterizava. Grande impacto foi observado para mudanças no comportamento dos surdos em relação à biblioteca. Sem as barreiras da comunidade por ter um membro surdo em sua equipe, todas as dúvidas poderiam ser esclarecidas dentro da língua de sinais e de sua eticidade, visto que este profissional apresenta profundo domínio das especificidades de bibliotecas.

Com a fluência em língua de sinais e com a identificação com o membro surdo da equipe, a biblioteca atua em direção à comunidade de surdos, apresentando-lhes a realidade da biblioteca. A constante educação acerca do uso da biblioteca e seus recursos foi ponto a se manter em consistência, a fim de treinar esse usuário para estar habilitado a usar qualquer biblioteca, e se sentir familiarizado e incluído mesmo fora da instituição.

A promoção de independência através de um programa de treinamento em competência em informação que envolvia treinamento, folders, informativos, palestras e instruções pessoais, juntamente com o controle de uso e usuários sistemático via software, trouxe um entendimento do movimento vivo que a coleção poderia fazer em ser consultada, e sair e voltar em empréstimos.

Anteriormente, os alunos tinham que reservar os materiais com assistência de um ouvinte por telefone ou preenchendo um formulário de papel. Agora eles podem fazer reservas online, de qualquer lugar, a qualquer hora. Além da necessidade de formação contínua de pessoal com ênfase na sensibilização, é importante o conhecimento de equipamentos e terminologia relacionada com a comunidade surda. Além da presença da Libras e da comunicação falada, o serviço de referência é configurado com uma estação de acesso ao software que permite aos usuários surdos a livre consulta ao acervo, além do também serviço de referência via e-mail.

Dentro deste panorama, pode-se afirmar que o grande diferencial da Biblioteca do INES é que, diferente de qualquer outra biblioteca que precisa se capacitar para receber a comunidade de surdos, no caso do INES, foi a comunidade de surdos que absorveu a Biblioteca. A realidade socio-identitária gerada a partir da dialética desta questão modifica o panorama da biblioteca como um todo, permitindo um olhar mais apurado sobre as questões da surdez.

\section{ACERVO ACESSÍVEL}

Embora o Ministério do Planejamento, Orçamento e Gestão tenha estimulado o uso do VLibras (BRASIL, 2016), um software de tradução Português-Libras, para muitas instituições públicas e escolas para surdos, ainda há uma grande população carente de surdos e pessoas que precisam de acesso à coleção de materiais em Libras e atendimento com acessibilidade. Uma vez que a biblioteca recebe obras como vídeos, dicionários e livros em Libras na sua coleção, além dos conhecidos recursos audiovisuais produzidos pela própria instituição, os vídeos tornaram-se um desafio e uma oportunidade para expandir o serviço de acesso aos usuários de uma maneira que acomoda as necessidades dos surdos e as pessoas com deficiência auditiva.

Os critérios de seleção e aquisição de acervo que compõem a Política de Desenvolvimento de Coleções da Biblioteca são essenciais para indicar a especificidade da comunidade a ser atendida, dando enfoque a seleção de obras que não apresentem barreiras linguísticas de acordo com o perfil dos usuários 
da Biblioteca (POLÍTICA..., 2015). A coleção é composta por vídeos com histórias em língua de sinais, vídeos feitos para crianças, jovens e adultos, vídeos legendados, dicionários de língua de sinais, materiais de ensino, informação geral sobre deficientes auditivos, coleções de periódicos temáticos, materiais de estímulo para aprendizagem de língua de sinais e jogos educativos em Libras.

A seleção segue normas visando mais diretamente recursos sobre educação de surdos, que exigem revisão frequente. Os materiais que datam do século XX e anteriores são mantidos, como um panorama da história da educação de surdos. Materiais em língua de sinais também seguem a mesma lógica, não são substituídos em virtude de apresentarem a evolução dos sinais brasileiros e a história dos mentores e de seu registro.

A coleção segue neutra apresentando obras que retratam tanto o oralismo e mais historicamente recente a abordagens do culturalismo, vertentes de abordagem na educação de surdos. Uma coleção coerente inclui materiais de vídeo que aborde o componente visual da língua de sinais e cultura surda. Importante ter como base os conteúdos em vídeo para servir a comunidade de surdos porque para este usuário a apropriação da informação é principalmente visual. Neste aspecto, o próprio INES produz diversos materiais em Libras, tanto em DVDs distribuídos nacional e internacionalmente de forma gratuita, e também através da TV INES, tanto em DVDs como por meio do aplicativo para aparelhos móveis (BRASIL, 2015).

A Biblioteca também elabora um mapeamento das editoras que têm seu enfoque em materiais didáticos e focados no ensino, tanto de alunos surdos, como de Libras para ouvintes, como a Arara Azul, LSB Vídeo, entre outras. A Biblioteca do INES permanece absorvida pela comunidade surda e este contato é matéria-prima enriquecida que trabalha em prol do atendimento ao usuário surdo e no que suas necessidades de informação primordialmente indicam.

\section{ORIENTAÇÕES PARA OUTRAS BIBLIOTECAS COM RELAÇÃO AO ATENDIMENTO DE PESSOAS SURDAS}

As Diretrizes para serviços de biblioteca para surdos da IFLA (2000) têm como objetivo informar os bibliotecários sobre as necessidades de informação das pessoas surdas e refere-se a todas as bibliotecas que têm pessoas surdas como qualquer parte de seu público potencial. Elas se aplicam a todos os tipos de bibliotecas, sejam bibliotecas: pública, escolar, universitária, especiais, especializadas, etc. São diretrizes gerais e, portanto, não contêm prescrições quantitativas, mas destinam-se a servir como critérios para estabelecer serviços para pessoas surdas e um meio de avaliar a integridade e qualidade desses serviços. Como estas orientações são de âmbito internacional, deve ser entendido que precisam ser ajustadas por limitações e especificidades nacionais e locais.

Neste ínterim, a acessibilidade por Sassaki (1997, p. 27) é composta por seis eixos: arquitetônico (sem barreiras no espaço físico), comunicacional (sem barreiras na comunicação), metodológico (sem barreiras nos métodos do fazer), instrumental (instrumentos sem limitações), programático (sem barreiras intrínsecas em políticas públicas, regras, leis, etc) e atitudinal (sem estereótipos, estigmas, preconceitos). No caso de acessibilidade para surdos em bibliotecas, fica clara a evidência na acessibilidade comunicacional e atitudinal, mas envolve por processo em cadeia também todos os outros eixos.

Alguns parâmetros podem ser indicados para iniciar uma acessibilidade comunicacional para as pessoas surdas, tais como: (1) explorar a sua própria coleção para selecionar livros sobre o surdo, surdez e tópicos relacionados, por exemplo, língua de sinais, problemas de audição, poluição sonora e surdez, etc, e preparar um catálogo para esses itens; (2) estabelecer contatos com fontes externas para solicitar materiais gratuitos sobre surdos e surdez; (3) adquirir materiais sobre os surdos e surdez, junto de algumas ferramentas de referência, como catálogos e outras fontes sobre editoras e organizações para surdos; (4) verificar a possibilidade de utilização de aparelhos eletrônicos para se comunicar com os usuários surdos, tais como Viable Brasil (serviço de tradução simultânea online Português-Libras), VLibras e ProDeaf (softwares de tradução Português-Libras), entre outros aplicativos em tablets e 


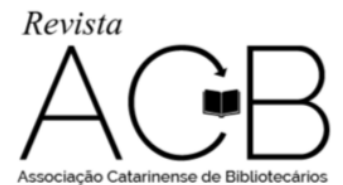

Acessibilidade e serviços inclusivos para minorias sociais: a biblioteca do Instituto Nacional de Educação de Surdos - Sarah Miglioli e Gilmara Almeida dos Santos

celulares que estão em constante atualização, etc; (5) considerar a possibilidade de contratar funcionários surdos qualificados que serão mais aptos a servir os usuários surdos e proporcionar a orientação adequada. Estes poderão também treinar outros funcionários a aprender Libras e/ou datilologia, além de serem prontamente melhor preparados a atender usuários surdos por fazerem parte da mesma comunidade linguística.

No que se refere ao eixo atitudinal, é preciso atentar para uma comunicação clara e precisa, a fim de evitar mal-entendidos e interações inadequadas. Para tal, algumas ações são propostas: (a) estar ciente das indicações na linguagem corporal ou gestuais não-verbais; (b) direcionar o foco na pessoa e não na deficiência; (c) aproximar o usuário com respeito e aceitação, em oposição à desaprovação ou reserva; (d) evitar o sentimento de pena; (e) oferecer assistência, do mesmo modo como para qualquer outro usuário em dificuldade ao usar a biblioteca; (f) conhecer bem a coleção sobre o tema e as necessidades especiais dos usuários com deficiência; (g) utilizar serviços orientados pelo design e experiência do usuário (user experience), sempre que necessário, para atender às necessidades especiais dos surdos.

Para evitar ruídos na comunicação ao trabalhar com ou atender uma pessoa com uma deficiência auditiva, torna-se relevante posicionar-se de frente para a pessoa diretamente ao falar, a fim de facilitar a leitura labial ou permitir que o indivíduo surdo tenha um melhor entendimento da sua fala. Caso o indivíduo seja um sinalizador, o bibliotecário deverá usar seu domínio da língua de sinais para se fazer entender ou interpretar uma questão de referência (BRASIL, 2004).

$\mathrm{O}$ acesso à informação de pessoas com surdez perpassa a situação onde uma pessoa com uma deficiência "invisível" necessita de ajuda. Nesse caso, se essa invisibilidade foi desvelada já é um passo importante no processo da acessibilidade. A partir de então cabe ao profissional uma atitude (eixo atititudinal)que atente para a compreensão das necessidades daquele indivíduo, tanto no âmbito da comunicabilidade (eixo comunicacional) quanto do conteúdo que o fez procurar a biblioteca.

Destaca-se a necessidade de agir naturalmente, orientando a pessoa também a se guiar pelas identificações visuais, proporcionando uma atmosfera favorável para o desenvolvimento da questão de referência (GROGAN, 1995). Os usuários surdos também podem instruir o bibliotecário sobre a forma de ajudá-los. Por outro lado, os bibliotecários precisam permitir que os usuários hajam de forma independente, para aprender e incorporar os processos e caminhos do uso da biblioteca para além de ter o atendimento priorizado, por conta da deficiência. Além de examinar as respostas comportamentais para usuários com necessidades específicas, deve-se avaliar a possibilidade de usar tecnologia assistiva para os surdos.

A fim de melhorar a abordagem para clientes com deficiência, é preciso focar no processo de capacitação. O processo de auto-educação pode envolver vários métodos, como (1) procurar especialistas acerca do tema; (2) buscar materiais de leitura e visualização de audiovisuais sobre o tema; e (3) aumentar contatos com pessoas surdas. Seja qual for o método selecionado, ele vai ajudar no acesso a uma permanência na sensação de ser e estar informado, de ter empatia e aceitação. Ao invés de ser intimidadora, a entrevista de referência vai gerar mútua a compreensão e o pedido de informação será satisfeito.

Samson (2011) recomenda que se designe um dos bibliotecários da equipe para de especializar na temática e nos alunos com necessidades especiais no caso de bibliotecas genéricas (públicas, universitárias, etc.). Não importa o tamanho da população surda de uma biblioteca, estabelecer um profissional específico demonstra o esforço que a instituição está fazendo para fortalecer essas relações. O profissional da informação designado pode trabalhar com outros departamentos, como o setor que serve estudantes com deficiência, para comunicar e divulgar os serviços da biblioteca que podem ser úteis a esses alunos.

As bibliotecas também podem estabelecer uma política específica para servir aos surdos (eixo programático), ou se esta população for pequena, uma política mais ampla para usuários com deficiência seria suficiente. Uma política simplificada pode fornecer orientações para a equipe da biblioteca no atendimento desses alunos. A própria existência da política serve como um símbolo para alunos com necessidades especiais que oferecer-lhes um serviço de qualidade é uma prioridade para a biblioteca. 
No que diz respeito às preferências de comunicação, sugere-se que as bibliotecas ofereçam múltiplas maneiras para usuários surdos e deficientes auditivos entrar em contato com os bibliotecários, que vão desde métodos digitais de comunicação, até a tradicional forma escrita (eixo metodológico). Ter guias ou tutoriais para solicitações comuns (pedidos de empréstimo entre bibliotecas, acesso a recursos exclusivos, etc.), em Português com áudio e legenda e Libras permite aos usuários surdos obter informações sem a frustração das barreiras de comunicação. Tal como acontece com guias para qualquer população de usuários, é aconselhável a utilização de linguagem clara e concisa e recursos visuais quando for o caso. Naturalmente, qualquer guia em vídeo deve incluir legendas para surdos e deficientes auditivos. Além de fornecer uma variedade de formatos de comunicação para os usuários, funcionários da biblioteca devem ser treinados na operação de todas as ferramentas de comunicação e serviços disponíveis para surdos.

Qualquer adaptação que ajude o elemento visual de comunicação irá beneficiar pessoas surdas (eixo arquitetônico). Uma iluminação que clareia o rosto é essencial para os leitores labiais que dependem em grande parte da leitura do rosto para entender as formações das diferentes palavras. Uma sinalização eficaz beneficia também aqueles surdos que não estão confortáveis em pedir ajuda de ouvintes. Um ambiente com uma boa acústica pode fazer toda a diferença para uma pessoa com deficiência de audição, móveis que absorvem o ruído (como tapetes e cortinas) fazem um ambiente mais utilizável acusticamente.

O bibliotecário precisa estar ciente das concessões que deverá fazer em termos de ruído e comportamento, se quiser ser receptivo à surdos em sua biblioteca. Quando pessoas com deficiência auditiva falam, podem não ser capazes de regular o volume da voz e o compasso da fala, o que exige uma comunicação mais prolongada e naturalmente um bibliotecário mais paciente. Dentro da biblioteca, os usuários surdos podem não estar cientes de que estão fazendo ruídos, quer com a voz ou de alguma outra forma, por exemplo, batendo portas ou na manipulação de materiais da biblioteca. O bibliotecário deve estar preparado para lidar com esses ruídos incomuns na biblioteca.

De maneira geral, uma biblioteca totalmente inclusiva para as pessoas surdas deve incorporar os seguintes elementos: divulgação do serviço; (b) avisos em associações e comunidades de surdos, departamentos de serviço social e audiologia e dentro das organizações especializadas; (c) artigos e anúncios nos meios de comunicação dirigidos às pessoas surdas em linguagem clara e concisa; (d) sites acessíveis com links para outros endereços especializados; (e) informações de vídeo sobre os serviços prestados pela biblioteca, com versão em Libras e legendas grandes e claras; (f) funcionários da biblioteca fazendo treinamento em Libras e leitura labial; (g) sinalização clara em todas as áreas, com imagens em Libras; (h) áreas de recepção e mesas de consultas todas devidamente equipadas com iluminação, fundos claros e uma boa acústica; (i) funcionários treinados sobre cultura surda, capaz de usar linguagem básica de sinal, com alguns funcionários treinados para padrões mais elevados e no alfabeto manual libras; (j) funcionários cientes das necessidades específicas dos surdos cegos, surdos com dificuldades de aprendizagem ou múltiplos comprometimentos; (k) treinamento de uso de serviços de assinatura de tradução da Libras; (l) versões em vídeo com sinais e legendadas dos folhetos informativos; (m) atividades infantis e adultas e apresentações com intérprete; (n) acervo disponível em uma gama de assuntos relacionados com as pessoas surdas e surdez; (o) acesso à base de dados nacionais e internacionais de formatos alternativos e serviço de empréstimo entre bibliotecas para pessoas surdas; (p) uso de TICs para incluir acessibilidade visual e tátil nos sites conforme leis de acessibilidade; (q) criação de um grupo consultivo formado por pessoas surdas.

No que tange o último item mencionado, a criação de um grupo de consulta garantirá a relevância dos serviços e, potencialmente, poupar recursos, evitando alterações que não são adequadas às pessoas surdas. Tecnologias facilitadoras e suporte de profissionais de comunicação (intérpretes de língua de sinais) serão necessários em todas as reuniões para assegurar a igualdade de acesso a todos os envolvidos no grupo. O grupo deve incluir pessoas que se identificam como membros da comunidade surda, ensurdecidos, dificuldades de audição e surdo cegos, surdos com dificuldades de aprendizagem, e aqueles com outros comprometimentos. 


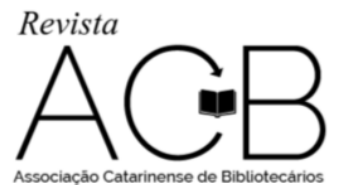

Acessibilidade e serviços inclusivos para minorias sociais: a biblioteca do Instituto Nacional de Educação de Surdos - Sarah Miglioli e Gilmara Almeida dos Santos

Conforme visto, a grande chave da acessibilidade em serviços para surdos está na língua de sinais, que mais do que uma necessidade de comunicação, natural pelo público em questão, perpassa toda e qualquer ação, ou seja, serviço voltado para as pessoas surdas. As necessidades conceituais, estruturais e de planejamento dos serviços a serem pensados para este público, mediante os eixos de acessibilidade mencionados, têm como referência a língua de sinais, que per compõe a base da estrutura das necessidades informacionais desta minoria.

\section{CONSIDERAÇÕES FINAIS}

Há muitas considerações especiais que precisam ser feitas, a fim de que as bibliotecas possam estar de acordo com as reivindicações de igualdade de oportunidades para usuários surdos. Formação de pessoal, desenvolvimento de coleções e educação do usuário são áreas a serem desenvolvidas. Estas considerações especiais podem ser implementadas ajustando-as com as prioridades existentes.

A importância destes serviços sendo introduzidos ou promovidos simultaneamente, como uma política da biblioteca, não pode ser subestimada, e uma sensibilidade para as necessidades das pessoas surdas e sua consequente aceitação significa que essas melhorias justificam um investimento de recursos. A capacitação da equipe também indica que qualquer pessoa surda que solicitar a qualquer membro da equipe da biblioteca receberá o mesmo nível de serviço que uma pessoa ouvinte receberia. Os seis eixos da acessibilidade de Sassaki (1997) retratam com clareza o amplo aspecto que a questão deve ser abordada.

O acesso à informação dos surdos deve partir do entendimento de quebra da barreira cultural, uma vez que a Libras é uma linguagem visual, e se as bibliotecas são percebidas como incentivadores somente da cultura do livro e do Português oral e escrito, então os surdos não estarão sendo incluídos socialmente. As bibliotecas têm a responsabilidade de informar tanto a comunidade surda e o público em geral sobre os aspectos da cultura surda, cuidados de saúde auditiva e métodos de comunicação e tecnologias para estas pessoas.

Todos os tipos de bibliotecas e redes de informação precisam continuar a melhorar os serviços para a comunidade surda. A equipe da biblioteca deve perceber que a comunidade surda é uma população heterogênea. As nove subpopulações distintas, cada uma com suas próprias necessidades de informação e de comunicação comprovam a diversidade deste público.

Tecnologia e serviços de informação para e sobre a comunidade surda é uma área que evolui rapidamente, e muitas das mudanças estão vinculados às leis e regulamentos sempre em atualização. É importante acompanhar os processos evolutivos das TICs, tecnologias assistivas e legislação no tema.

Com a presença constante e maciça de usuários surdos, a participação destes indivíduos em todos os aspectos, como agentes, consultores e usuários pode desempenhar um papel cada vez maior no desenvolvimento de soluções para os problemas associados ao fornecimento de serviços de biblioteca e de informação para e sobre pessoas surdas.

\section{REFERÊNCIAS}

ANDRADE, Suélen; LUCAS, Elaine Rosangela Oliveira; NASCIMENTO, Maria de Jesus. Acessibilidade para usuários da informação com deficiência: um estudo de artigos em biblioteconomia e ciência da informação. Biblionline, João Pessoa, v. 11, n. 1, p. 1-20, 2015.

BISOL, Cláudia Alquati. Estudantes surdos no ensino superior: reflexões sobre a inclusão. Cadernos de Pesquisa, v. 40, n. 139, p.147-172, jan./abr. 2010.

BRASIL. Decreto n ${ }^{\circ}$ 5.626, de 22 de dezembro de 2005. Disponível em: 


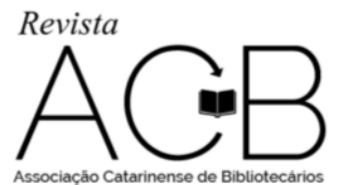

Acessibilidade e serviços inclusivos para minorias sociais: a biblioteca do Instituto Nacional de Educação de Surdos - Sarah Miglioli e Gilmara Almeida dos Santos

<http://www.planalto.gov.br/ccivil_03/_ato2004-2006/2005/decreto/d5626.htm>. Acesso em: 11 jul. 2016.

BRASIL. Ministério da Educação. Instituto Nacional de Educação de Surdos. Conheça o INES. Rio de Janeiro: INES, 2015. Disponível em: < http://www.ines.gov.br/conheca-o-ines>. Acesso em: 11 jul. 2016.

BRASIL. Ministério da Educação. SINAES. Brasília: MEC, 2003. Disponível em: <http://portal.mec.gov.br/arquivos/pdf/sinaes.pdf>. Acesso em: 11 jul. 2016.

BRASIL. Ministério do Planejamento, Orçamento e Gestão. Governo lança conjunto de aplicativos digitais para surdos: tradutor VLibras pode ser baixado para computadores e dispositivos móveis, 05/05/2016. Disponível em: <http://www.planejamento.gov.br/assuntos/logistica-e-tecnologia-dainformacao/noticias/governo-lanca-conjunto-de-aplicativos-digitais-para-surdos>. Acesso em: 11 jul. 2016.

BRASIL. Secretaria de Educação Especial. O tradutor e intérprete de língua brasileira de sinais e língua portuguesa. Brasília: MEC, 2004.

CAPOVILLA, Fernando. Processos logográficos, alfabéticos e lexicais na leitura silenciosa por surdos e ouvintes. Estudos de Psicologia, v. 10, n. 1, p. 15-23, 2005.

CONEGLIAN, André Luís Onório; CASARIN, Helen de Castro Silva. Biblioteca inclusiva: perspectivas internacionais para o atendimento a usuários com surdez. VII ENCONTRO ENANCIB VII, 2006.

Disponível em: <http://portalppgci.marilia.unesp.br/viewabstract.php?id=305>. Acesso em: 11 jul. 2016.

CRUZ, José Ildon Gonçalves da; DIAS, Tárcia Regina da Silveira. Trajetória escolar do surdo no ensino superior: condições e possibilidades. Revista Brasileira de Educação Especial, v.15, n.1, p.65-80, 2009.

FONSECA, Cintia Cibele Ramos Fonseca; GOMES, Gicele Farias; VANZ, Samile Andréa de Souza. Acessibilidade e inclusão em bibliotecas: um estudo de caso. XVII SNBU, 2012, Gramado - RS, 16 a 21 de setembro de 2012. Disponível em:

<https://www.lume.ufrgs.br/bitstream/handle/10183/61049/000864667.pdf?sequence=1>. Acesso em: 11 jul. 2016.

GROGAN, Denis. A prática do serviço de referência. Brasília: Briquet de Lemos, 1995.

HAGEMEYER, Alice Lougee. We have come a long way. Library Trends, v. 41, n. 1, p. 4-20, summer 1992.

IBGE. Censo Demográfico 2010. Disponível em:

<http://www.ibge.gov.br/estadosat/temas.php?tema=censodemog2010_defic>. Acesso em: 11 jul. 2016.

IFLA Relatórios Profissionais, no. 24. Diretrizes para serviços de biblioteca para surdos. 2a Edição. Editado por John Michael Day. 2010. Disponível em: 〈especial.futuro.usp.br/documentos/guiaifla.rtf〉. Acesso em: 11 jul. 2016.

ISHIMOTO, Adonai Takeshi; RAMÃO, Lucília Maria Sousa. O silêncio dos ouvintes: o biliotecário em relação ao leitor surdo. Biblionline, João Pessoa, v. 11, n. 2, p. 31-42, 2015. Disponível em:

<http://periodicos.ufpb.br/index.php/biblio/article/viewFile/26719/15187>. Acesso em: 11 jul. 2016. 


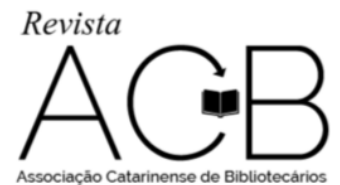

Acessibilidade e serviços inclusivos para minorias sociais: a biblioteca do Instituto Nacional de Educação de Surdos - Sarah Miglioli e Gilmara Almeida dos Santos

KARNOPP, Lodenir Becker. Cultura surda na contemporaneidade: negociações, intercorrências e provocações. Canoas, RS : Ed. da ULBRA, 2011.

LE COADIC, Yves François. A Ciência da Informação. Brasília: Briquet de Lemos, 2004.

MANENTEL, Milena Valelongo; RODRIGUES, Olga Maria Piazentin Rolim; PALAMIN, Maria Estela Guadagnuci. Deficientes auditivos e escolaridade: fatores diferenciais que possibilitam o acesso ao ensino superior. Rev. bras. educ. espec., v.13, n.1, Marília, jan./abr. 2007.

MIRANDA, Sulamita Nicolau de; MIRANDA, Marcos Luiz Cavalcanti de. Bibliotecas universitárias e a acessibilidade aos usuários surdos e com deficiência auditiva. Inf. Prof., Londrina, v. 4, n. 2, p. 04 - 19, jul./dez. 2015. Disponível em: <http:www.uel.br/revistas/infoprof/ 4>. Acesso em: 11 jul. 2016.

MONTEIRO, Myrna Salerno. História dos movimentos dos surdos e o reconhecimento da Libras no Brasil. ETD - Educação Temática Digital, Campinas, v. 7, n. 2, p.292-302, jun. 2006. Disponível em: <http://www.ssoar.info/ssoar/bitstream/handle/document/10178/ssoar-etd-2006-2-monteirohistoria_dos_movimentos_dos_surdos.pdf?sequence=1>. Acesso em: 11 jul. 2016.

POLÍTICA DE DESENVOLVIMENTO DE COLEÇÕES DA BIBLIOTECA DO INES. Rio de Janeiro: INES, 2015.

QUADROS, Ronice. Educação de surdos: a aquisição da linguagem. Porto Alegre: Artmed, 2008.

RELATÓRIO ANUAL DA BIBLIOTECA DO INES. Rio de Janeiro: INES, 2015.

ROSA, Fabiano Souto: Literatura surda: criação e produção de imagens e textos. In: ETD - Educação Temática Digital, v. 7, n. 2, pp. 58-64, 2006. Disponível em: <http://nbn-resolving.de/urn:nbn:de:0168ssoar-101589>. Acesso em: 11 jul. 2016.

SAMSON, Sue. Best practices for serving students with disabilities. Reference Services Review, v. 39, Issue 2, pp.260 - 277, 2011.

SANTOS, M. P. ; DINIZ, C. N.; SÁ, N. A. A importância da acessibilidade nas bibliotecas públicas. VIII Seminário Nacional de Bibliotecas Braille: Cultura, Educação e Inclusão, São Paulo, 28 a 30 de abril de 2014.

SASSAKI, Romeu K. Inclusão: construindo uma sociedade para todos. Rio de Janeiro: WVA, 1997.

STROBEL, Karin. História da Educação de Surdos. Florianópolis: UFSC, 2009. Disponível em: <http://www.libras.ufsc.br/colecaoLetrasLibras/eixoFormacaoEspecifica/historiaDaEducacaoDeSurdos/a ssets/258/TextoBase_HistoriaEducacaoSurdos.pdf>. Acesso em: 11 jul. 2016.

SKLIAR, Carlos. (Org.) A surdez: um olhar sobre as diferenças. Porto Alegre: Mediação, 2005.

SOUSA, Clemilda dos Santos Sousa. Biblioteca universitária e comunidade surda: uma proposta de acessibilidade à informação. XVI Seminário Nacional de Bibliotecas Universitárias, 2010.

STROBEL, Karin. As imagens do outro sobre a cultura surda. Florianópolis: UFSC, 2008. 


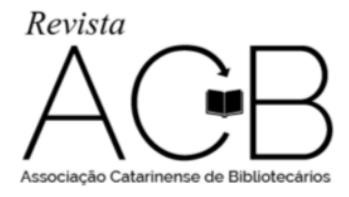

\title{
ACCESSIBILITY AND INCLUSIVE SERVICES FOR SOCIAL MINORITIES: THE LIBRARY OF THE BRAZILIAN INSTITUTE FOR DEAF EDUCATION
}

\begin{abstract}
This article discusses the role of the library as a propeller of access and promotion of information for social minorities. It exposes the importance of the library's performance in diversity, citizenship and social inclusion. This is an account of experience in accessibility for the deaf in the library of the National Institute of Deaf Education. It presents accessibility parameters for the deaf and proposes measures for the integration of the deaf individual into the library.
\end{abstract}

Keywords: Accessibility. Disabled person. Hearing deficiency. Deaf people. Social minorities.

RECEBIDO EM: 09-10-2016

ACEITO EM: 13-03-2017 